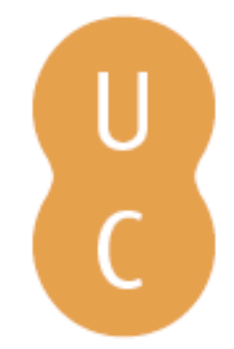

\title{
Rnmpalina
}

\section{Apontamento sobre D. Francisco Manuel de Melo, a história da guerra da Catalunha e os papéis da restauração}

\author{
Autor(es): $\quad$ Anastácio, Vanda \\ Publicado por: Imprensa da Universidade de Coimbra; Ediciones Universidad \\ URL \\ persistente: URI:http://hdl.handle.net/10316.2/31523 \\ DOI: $\quad$ DOI:http://dx.doi.org/10.14195/978-989-26-0245-5_13 \\ Accessed : $\quad$ 26-Apr-2023 11:25:34
}

A navegação consulta e descarregamento dos títulos inseridos nas Bibliotecas Digitais UC Digitalis, UC Pombalina e UC Impactum, pressupõem a aceitação plena e sem reservas dos Termos e Condições de Uso destas Bibliotecas Digitais, disponíveis em https://digitalis.uc.pt/pt-pt/termos.

Conforme exposto nos referidos Termos e Condições de Uso, o descarregamento de títulos de acesso restrito requer uma licença válida de autorização devendo o utilizador aceder ao(s) documento(s) a partir de um endereço de IP da instituição detentora da supramencionada licença.

Ao utilizador é apenas permitido o descarregamento para uso pessoal, pelo que o emprego do(s) título(s) descarregado(s) para outro fim, designadamente comercial, carece de autorização do respetivo autor ou editor da obra.

Na medida em que todas as obras da UC Digitalis se encontram protegidas pelo Código do Direito de Autor e Direitos Conexos e demais legislação aplicável, toda a cópia, parcial ou total, deste documento, nos casos em que é legalmente admitida, deverá conter ou fazer-se acompanhar por este aviso.

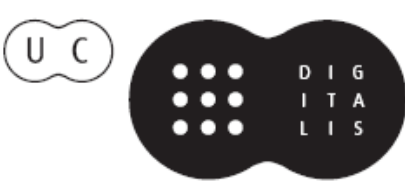


Marta Teixeira Anacleto

Sara Augusto

Zulmira Santos

Coordenação

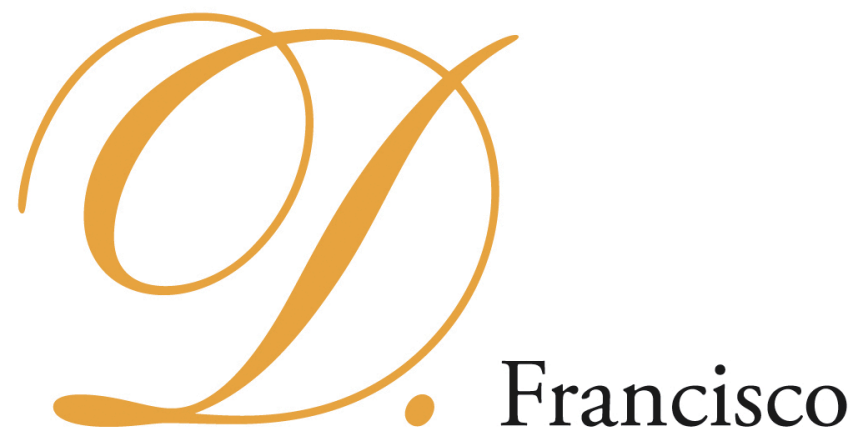

Manuel de Melo e o

Barroco Peninsular 


\title{
EDIĈ̣̃O
}

Imprensa da Universidade de Coimbra Ediciones Universidad Salamanca

\section{COORDENAÇÃo EDITORIAL}

Imprensa da Universidade de Coimbra

URL: http://www.uc.pt/imprensa_uc

Vendas online: http://www.livrariadaimprensa.com

\section{CONCEPÇÃO GRÁFICA}

António Barros

\section{REVISÃO TEXTO}

Sara Augusto

\author{
Pré-Impressão, Impressão e ACABamento \\ www.artipol.net
}

\section{IS B N}

978-989-26-0044-4 (Portugal)

978-84-7800-194-1 (Espanha)

DEPósito LEGAL

$311680 / 10$

OBRA PUBlicada COM O APOIO DE:

FCT Fundação para a Ciência e a Tecnologia

MINISTÉRIO DA CIÊNCIA, TECNOLOCIA E ENSINO SUPERIOR Portugal

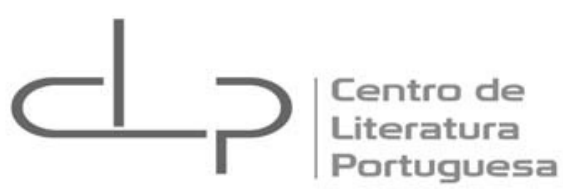

A presente publicação insere-se no Grupo "Poéticas" (coordenação de Marta Teixeira Anacleto) do Centro de Literatura Portuguesa, Unidade de I\&D financiada pela Fundação para a Ciência e a Tecnologia, ao abrigo do Programa Operacional Ciência e Inovação 2010.

(C) Agosto 2010

IMPRENSA DA UNIVERSIDADE DE COIMBRA

EDICIONES UNIVERSIDAD DE SALAMANCA 
Marta Teixeira Anacleto

Sara Augusto

Zulmira Santos

Coordenação

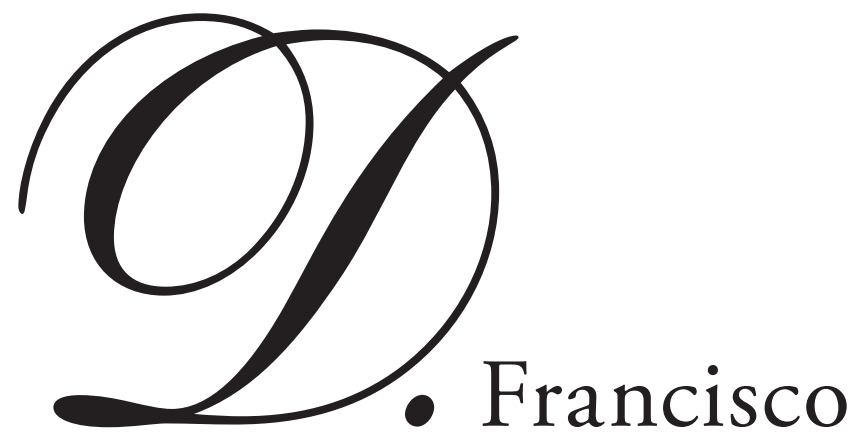

Manuel de Melo e o Barroco Peninsular

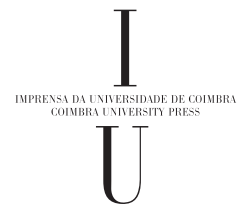


PARTE III

MODALIDADES DE ESCRITA DO BARROCO EM D. Francisco Manuel de Melo 


\author{
Vanda Anastácio \\ Universidade de Lisboa
}

\title{
APONTAMENTO SOBRE D. FRANCISCO MANUEL DE MELO, A HISTÓRIA DA GUERRA DA CATALUNHA E OS PAPÉIS DA RESTAURAÇĀO
}

A Historia de los movimientos y separación y Cataluña ${ }^{1}$ de D. Francisco Manuel de Melo tem sido geralmente considerada como uma narração feita em primeira máo de factos testemunhados pelo seu autor, apesar de este ter sido, de facto, cronista de uma guerra que praticamente não presenciou. Com efeito, tendo sido nomeado para assistir ao Marquês de Velez em Junho de 1640, Melo só permaneceu na Catalunha entre 25 de Novembro de 1640 e finais de Dezembro do mesmo ano, data em que, como se sabe, foi detido e enviado a Madrid para ser interrogado acerca do seu possível envolvimento na conspiraçáo portuguesa que levou à Restauração ${ }^{2}$. Como recordou Estruch Tobella em anos recentes, a circunstância de a obra não narrar toda a guerra, suspendendo o relato em 1641, com a derrota dos castelhanos em Montjuic, longe de corresponder a uma interrupçáo motivada pela ausência de dados testemunhais, parece decorrer de uma intenção política e traduzir o desejo de terminar com a apresentação da derrota do exército castelhano como «um final exemplar», adequado aos objectivos de um texto que, como todo o discurso historiográfico produzido por D. Francisco Manuel, se apresenta como uma liçáo destinada a provocar no leitor uma reflexáo moral ${ }^{3}$.

O mesmo historiador demonstrou que, ao contrário do que fora afirmado por autores como B. N. Teensma ${ }^{4}$, Jean Colomès e outros, para narrar os acontecimentos de que fala

\footnotetext{
${ }^{1}$ Clemente Libertino [pseud. D. Francisco Manuel de Melo], Historia de los movimientos y separación y Cataluña y de la guerra entre la Magestad Católica de Don Felipe el Cuarto, Rey de Castilla y de Aragón, y la Diputación General de aquel Principado. Dedicada, ofrecida y consagrada a la santidad del beatíssimo Padre Inocêncio décimo, Pontifice Sumo Máximo romano. Lisboa: 1645 [reed.: 1692 e 1696; trad. francesa: 1654; 1ª ed. espanhola: 1808].

2 Jean Colomès, La critique et la satyre de D. Francisco Manuel de Melo. Paris, P.U.F., 1969, p. XXXV, sublinha que Velez recebeu a ordem de prisão de Melo juntamente com a notícia da Restauração de Portugal.

${ }^{3}$ Joan Estruch y Tobella, "Las fuentes de Guerra de Cataluña, de D. Francisco Manuel de Melo», Criticón, Toulouse: no 44, 1988, pp. 7-24: «La obra termina en 1641 con la batalla de Montjuich, aunque la Guerra se prolongaria hasta 1652. Ello puede ser debido tanto al deseo de centrarse en lo que él conoció más directamente como al de concluir su obra com un final ejemplar, la derrota del ejército castellano a las puertas de Barcelona, adecuado a sus propósitos políticos».

${ }^{4}$ Benjamin Nicolas Teensma, Don Francisco Manuel de Melo, 1608-1666: inventario genral de sus ideas, Gravenhage: Martinus Nijhoff, 1966; Jean Colomès, La critique et la satyre de D. Francisco Manuel de Melo, pp. 175-251.
} 
nesta sua obra, em grande parte escrita na prisão, D. Francisco Manuel não se limitou a relatar uma experiência pessoal, mas lançou mão das fontes impressas a que foi tendo acesso 5 . O facto de ter podido manter uma intensa comunicaçáo com o mundo exterior durante os cerca de onze anos que permaneceu encarcerado encontra-se documentado na numerosa correspondência que D. Francisco escreveu nessa época, e explica que o autor tenha podido recorrer a esses materiais: apesar de ser prisioneiro de Estado pôde escrever e receber cartas, visitas e livros, bem como tecer, manter e alimentar redes de sociabilidade no exterior do cárcere, um aspecto estudado em artigo recente por Maria de Lurdes Correia Fernandes ${ }^{6}$.

Como recordou Joel Serrão, algumas das fontes indirectas do texto da história das guerras da Catalunha são os modelos clássicos na forma de conceber, mas também de escrever a história: Salústio, Tito Lívio e Tácito eram historiadores que D. Francisco conhecia bem, muito provavelmente desde a juventude, ainda que mencione também autores mais modernos, como Diego Hurtado de Mendoza (1503-1575), cuja Guerra de Granada chega a citar ${ }^{7}$. Qualquer destes autores poderia ter sido lido por Melo em várias épocas da sua vida, mas não seria difícil voltar a consultar, então, as suas obras.

Mais directamente relacionadas com o tema que gostaríamos de desenvolver aqui, são as fontes contemporâneas de D. Francisco Manuel de Melo e, muito especialmente, a inclusão no seu discurso de adaptaçóes reconhecíveis de passagens de quatro obras então muito recentes - três delas impressas em 1641 e uma em 1642 - um facto de que Joan Estruch Tobella deu conta num estudo de $1988^{\circ}$. Sáo elas:

Proclamacion católica a la Magestad piadosa de Felipe el Grande Rey de las Españas, y Empe-rador de las Indias nuestro seńor. Los Conselleres Conseio de Ciento de la ciudad de Barcelona, Impreso em Barcelona e agora em Lisboa por António Alvares, Impressor del Rey nosso Senhor, $1641^{9}$.

Epitome de los princípios y progresos de las guerras de Catalunha de los años 1640 1641 y señalada victoria de Montjuyque. Escrivelo el Pe Gaspar Sala Por mandado de los señores Deputados. En Barcelona. Por Pedro Lacavalleria. Anno 1641. E agora Impresso em Lisboa pello mesmo original, Por António Aluarez, Impressor del Rey nosso senhor. Anno 1641.

\footnotetext{
${ }^{5}$ Joan Estruch y Tobella, «Las fuentes de Guerra de Cataluña, de D. Francisco Manuel de Melo». Este estudioso sublinha que entre os cinco livros que compóem a História de los movimientos y separación de Cataluña apenas os livros quarto e quinto se referem, em parte, a acontecimentos directamente presenciados por D. Francisco.

${ }^{6}$ Maria de Lurdes Correia Fernandes, «Des sociabilités qui surmontent les distances. Autour du réseau des relations intellectuelles de Francisco Manuel de Melo» in Arquivos do Centro Cultural Português. Paris-Lisboa: 2005, pp. 33-44.

7 Joel Serrão, «Introdução» in D. Francisco Manuel de Melo, Alteraçôes de Évora: 1637. Edição de Joel Serrão. Lisboa: Portugália, 1967.

${ }^{8}$ No mesmo trabalho, Estruch y Tobella avança, como possibilidade de fontes indirectas da obra de D. Francisco, os papéis de José Pellicer de Tovar, Idea del principado de Cataluña Anvers, 1642 e Alberto Tormé y Liori, Miscelaneos históricos y políticos sobre la guerra de Cataluña desde el año 1639, que circulava manuscrito.

${ }^{9}$ Deste opúsculo conserva-se na Biblioteca Nacional de Lisboa, também, a versão editada em Barcelona: Proclamacion católica a la Magestad piadosa de Felipe el Grande Rey de las Españas, y Emperador de las Indias nuestro señor. Los Conselleres Conseio de Ciento de la ciudad de Barcelona. Barcelona: Sebastian y Iayme Mathevad, 1641.
} 
Noticia Universal de Catalunha en Amor servicios y Finezas admirable, en agravios opresiones y desprecios sufrida, En constituciones privilégios y libertades valerosa, en alteraciones movimientos y debates disculpada, en defensas repulsas e evasiones encogida, En Dios Razón y Armas prevenida y siempre en su Fidelidad constante A los muy Illustres Conselleres, y Sábio Consejo de Ciento de la ciudad de Barcelona, En Lisboa, por António Alvarez Impressor del Rey. 1641.

Apoyos de la verdad catalana contra las obieciones de una justificación, que se hizo en nombre del rey Catholico contra esta província com los cargos que injustamente se le impusieron per unos papeles volantes y descargo a ellos. De 1642.

Estas fontes merecem a nossa atenção.

Com efeito, se quisermos caracterizar estes impressos, teremos que ter em mente «a guerra de tinta» (na expressão de Nuria Florensa i Soler ${ }^{10}$ ) que, tal como se verificava na Europa Central desde o início da Guerra dos Trinta Anos, acompanhou as lutas separatistas da Catalunha e de Portugal em 1640. Refiro-me às intensas campanhas de propaganda assentes em panfletos impressos de larga difusão que secundaram as campanhas militares, as negociaçóes financeiras e as acçóes de espionagem e de contra-espionagem entre as partes envolvidas. Os contemporâneos designavam estes panfletos, simplesmente, por papéis. E é assim que D. Francisco Manuel de Melo se lhes refere, quando na sua História da Cataluña alude aos "papeles que se han escrito en Cataluña» que circulavam sobre os acontecimentos ${ }^{11}$.

A importância dos papéis da Restauração para o estudo dos anos 1640 a 1668 tem sido referida por estudiosos como Artur Anselmo, Fernando Bouza Alvarez, Eurico Gomes Dias $^{12}$ e, muito especialmente, por João Francisco Marques, que estudou as colecçóes portuguesas inventariadas e pôde náo só avançar números relativos aos papéis que terão circulado em apoio do partido português (pelo menos 783) mas também sublinhar a variedade de idiomas neles utilizados (português, castelhano, latim, neerlandês, francês, italiano e cataláo) $)^{13}$.

Tentei provar noutro lugar, que uma parte muito considerável dos impressos portugueses teve o patrocínio directo do Duque de Bragança na sua produção e disseminação ${ }^{14}$,

${ }^{10}$ Nuria Florensa i Soler, «La republica catalana en la guerra contra Felipe IV: el Consell de Cent: más que un gobierno municipal», Espacio, tiempo y forma, Série IV, Historia Moderna, no 12, 1999, pp. 181-198 e também Nuria Florensa i Soler, "La Republica catalana de 1641: un foc d'encendalls» in Butlletí de la Societat catalana d'Estudis Històrics, $\mathrm{n}^{\circ} 15,2004$, pp. 75-88.

${ }^{11}$ Nos livros III, $\$ 39$, IV, $\$ 113$ e V $\$ 135$. Citamos pela edição de Joan Estruch y Tobella: D. Francisco Manuel de MELO, Guerra de Cataluña. Barcelona: Fontamara, 1982.

${ }^{12}$ Artur Anselmo, Estudos de História do Livro. Lisboa: Guimarães Editores, 1997; Fernando Bouza Alvarez, Imagem e Propaganda, Capitulos de Historia cultural del reinado de Felipe II. Madrid: Ediciones Akal, 1998 e Fernando Bouza Alvarez, «Cartas, traças e sátiras. Política, cultura e representaçóes no Portugal dos Filipes 15801668", Portugal no tempo dos Filipes. Lisboa: Cosmos, 2000, pp. 19-38; Eurico Gomes Dias, "As primeiras Gazetas em Portugal: uma apresentação", Gazetas da Restauração: [1641-1648]. Uma revisão das estratégias diplomáticas portuguesas (edição transcrita). Lisboa: Ministério dos Negócios Estrangeiros, 2006, pp. XIII-XXI.

${ }^{13}$ João Francisco Marques, A Parenética Portuguesa da Restauração 1640-1668. A Revolta e a Mentalidade, 2 vols. Porto: INIC, 1989.

${ }^{14}$ Vanda Anastácio, «'Heróicas virtudes e escritos que as publiquem'. D. Quixote nos papéis da Restauração", Revue der iberischen Halbinseln, no 28. Berlim: Instituto Ibero-Americano, 2007, pp. 117-136. 
uma interferência que explica a rapidez com que estes panfletos passavam pelas três instâncias do sistema de censura vigente em Portugal ${ }^{15}$, bem como a ausência frequente da transcrição de licenças dos censores nos papéis que circularam nos primeiros anos que seguiram à aclamação, e está patente na correspondência trocada entre o soberano e os seus representantes nas cortes estrangeiras. Os dados em presença permitem ainda verificar que, apesar de se poderem identificar cerca de uma dúzia de impressores em actividade no reino, entre a aclamaçáo de D. João IV e a morte deste, o mercado editorial português se encontrou dominado por um grupo de apenas seis, todos eles exercendo a sua actividade em Lisboa ${ }^{16}$. São eles: Paulo Craesbeeck, Lourenço de Anveres, Jorge Rodrigues, Domingos Lopes Rosa, Manuel da Silva e António Álvares (que se intitula «Impressor de el Rey»).

Uma parte dos papéis que estes profissionais publicaram nestes anos foi impressa «à sua custa», informação que pode ler-se nas páginas de rosto de muitas das suas obras, mas uma proporção significativa destas publicaçôes foi estampada «à custa» de um tal «Lourenço de Queirós», cujo nome surge acompanhado pela indicaçáo: «livreiro do Estado de Bragança». Uma primeira sondagem entre os impressos conservados na Biblioteca Nacional de Lisboa permitiu-nos verificar que o nome desta personagem se encontra expressamente mencionado em obras provenientes das oficinas dos mesmos seis impressores. A proximidade entre este livreiro e o rei, (ou os círculos afectos à corte), é reivindicada pelo próprio Queirós em alguns dos paratextos das obras a que associou o seu nome ${ }^{17}$. Confirmam ainda esta proximidade, não só o facto de Queirós se identificar como «livreiro do Estado de Bragança» mas, também, os elementos dispersos por papéis desta época, relativos a outros privilégios que lhe foram concedidos pelo rei.

Note-se que o patrocínio real deste tipo de propaganda não constituiu um caso isolado no contexto europeu da época. Pela mesma época Filipe IV e o Duque de Olivares apoiaram a publicaçáo de obras de propaganda contra Portugal e contra a Catalunha, e o profundo envolvimento da França nos conflitos peninsulares traduziu-se, também, no patrocínio directo de Luís XIII à criação e à disseminação de estampas e de libelles satíricos dentro e fora do espaço ibérico. A longa duraçáo das guerras entre a Espanha e a França contribuiu mesmo para o aparecimento e difusão de uma personagem caricatural recorrente nos papéis

${ }^{15}$ Em vez da duração média de um a dois anos entre a entrega de um original na tipografia e o seu aparecimento no mercado passou-se a intervalos inferiores a um mês, de semanas, ou até de dias em casos específicos.

${ }^{16}$ Veja-se Maria Isabel Loff, Impressores, Editores e Livreiros no século XVII em Lisboa, separata de Arquivo de Bibliografia Portuguesa, anos X-XII, 1964-1966, e Margarida Ortigão Ramos, Tratamento bibliográfico de uma miscelânea de folhetos sobre a Restauração de Portugal 1641-1667 (exemplar policopiado). Coimbra: Universidade de Coimbra, 1980.

${ }^{17}$ É o caso, por exemplo, da Dedicatória a D. Teodósio, herdeiro da Casa Real, que figura no papel impresso em 1642 por Domingos Lopes Rosa intitulado Regra Militar offerecida ao Sereníssimo Príncipe Dom Theodosio nosso Senhor. Com hua Relaçam do que fez a Villa de barcellos, depois que foy aclamado Rey, \& Snör Sua Magestade, atè o primeiro de Ianeiro 1642, Impressa á custa de Lourenço de Queirós Livreiro da Casa de Bragança. Lisboa: na Officina de Domingos Lopes Rosa, 1642. Na qual se pode ler o seguinte: «esta Relação, me enviarão dous criados de V. A. para as imprimir, das quais a Relação vinha já offerecida a V. A. E assi me pareceo que cometia crime, em não buscar affectuosamente a mesma protecção; pois como Official tão antigo da Real Casa de Bragança, corre por conta de V. A. apadrinhar as obras, que saírem por ordem minha». 
franceses, chamada «l'Espagnol» ${ }^{18}$. O empenhamento pessoal do monarca português foi secundado pelo envolvimento dos seus homens de confiança na produção de textos difundidos através dos circuitos de venda ambulante de folhetos e papéis: António Pais Viegas, Francisco Velasco de Gouveia, João Pinto Ribeiro, António de Sousa de Macedo, o Conde de Penaguiáo, etc., foram autores de papéis, o que nos parece revelador quanto à importância que era atribuída entáo à sua produção.

O que pretendemos sublinhar aqui é a participação de D. Francisco Manuel de Melo nesta guerra de papel e de tinta «alimentando-a», por assim dizer, com pelo menos sete títulos, comparáveis aos papéis de propaganda da Restauração que acabamos de brevemente caracterizar, pelos objectivos, pelo tom e pelo modo de produção e circulação. É ele próprio que esclarece, por exemplo, no Hospital das Letras, que a Historia de los movimientos y separación y Cataluña, (publicada em 1645, no momento em que caíra em desgraça junto de D. João IV), resultara de uma encomenda deste género, inicialmente feita pela facçáo espanhola e posteriormente destinada ao rei de Portugal. Significativamente, ao referir o modo como começou a reunir materiais para compor o seu papel alude, quer aos dados da sua experiência pessoal, quer aos escritos que circulavam então. Conta:

Ora tinha El-Rei de Espanha ordenado ao general daquela guerra fizesse, pela pessoa mais hábil que no exército se achasse, pôr em memoria os progressos dela. Não sei porque causa fui eu o escolhido para este efeito, não sendo o mais ocioso da companhia; mas foi, sem falta, porque nasci em signo de tabalião. Recolhi logo, a este fim com grande pureza subministradas, as relaçôes de tudo, passando-me tudo o que se obrava, ou pelas mãos ou pelos olhos $^{19}$.

$\mathrm{Na}$ narraçáo que se segue, a obra é apresentada como um «serviço à república» e o seu último destinatário, apesar de a obra ter saído dedicada ao papa, o rei de Portugal:

Porém, quando eu já me dispunha a dar princípio à minha história, eis que me mandou prender el-Rei [de Espanha, entenda-se], por português, sem mais delito que o nascimento. Andaram os tempos, cheguei á pátria donde, depois de muito bem pisado e acalcanhado, à imitação de nosso Ovídio em Ponto (e tanto que foi em o ponto mais cruel da minha vida), continuei a escritura começada desse livro. E porque a este tempo vagavam, pelo mundo, muitas falsas opiniōes de um tão grave negócio, entendi fazer serviço á república, manifestando-o assim como ele fora e não como o ódio ou o amor, que são dous grandes pintores, o haviam pintado no lenço da eternidade, com mão diferente.

Quando se começou, aquele livro era oferecido a El-Rei de Castela; quando se acabou devia oferecer-se a El-Rei de Portugal. Partiu na contenda o discurso, acolhendo-me à Igreja e fazendo que o livro fosse posto aos benditos pés da santidade de Inocêncio X, por

${ }^{18}$ Vejam-se algumas reproduçóes desta caricatura em Alexandra Reis Gomes (coord.), Estampa e caricatura política estrangeira sobre Portugal: a doação Rau. Lisboa: Museu Nacional de Arte Antiga, 2000, e em Helène Ducini, Faire voire, faire croire. L'opinion publique sous Louis XIII. Champ Vallon, 2003. Sobre a problemática das guerras de panfletos políticos veja-se também Christian Jouhaud, Mazarinades: la Fronde des mots. Paris: Gallimard, 1985, e Christian Jouhaud, La Main de Richelieu, ou le pouvoir cardinal. Paris: Gallimard, 1991.

19 Jean Colomès, Le dialogue 'Hospital das Letras' de D. Francisco Manuel de Melo. Paris: Fundação Gulbenkian-Centre Culturel portuguais, 1970, p. 94. 
mãos de Jerónimo Bataglino, cujo primeiro exemplar mandou se colocasse na Livraria do Vaticano $^{20}$.

Foi neste mesmo espírito que, em 1646, D. Francisco respondeu com o Ecco politico ${ }^{21}$ a um panfleto castelhano a que João Pinto Ribeiro também respondera em $1645^{22}$ e, em 1647 engrossou a avalanche de papéis que deploram o atentado a D. Joáo IV, com a publicaçáo do Manifiesto de Portugal 3 . Tal como aconteceu com a maior parte dos autores portugueses de papéis partidários da Restauração (que usaram a situação de assimetria linguística explorando o acesso que esta lhes permitia à língua do inimigo), Melo redige estes textos em castelhano, um pormenor significativo já notado por António Camóes Gouveia em $1987^{24}$. A sua actividade panfletária continuou durante o reinado de D. Afonso VI, com a publicação de obras como as Epanáphoras de varia história, a Declaracion que por el reyno de Portugal ofrece e a Demonstración que por el reyno de Portugal, estas últimas assinadas com o pseudónimo de «Doctor Geronimo de Santa Cruz», publicadas em 1660, 1663 e $1664^{25}$.

O facto de entre as fontes da sua história da guerra de Catalunha, se contarem "papéis» deste tipo, permite caracterizar D. Francisco Manuel não só como produtor de impressos de propaganda, mas também, como consumidor destes. Este aspecto pode ajudar-nos a entender melhor, não só o modo como Melo encarou a escrita da tal história de «uma acção particular» a que se refere no Hospital das Letras ${ }^{26}$ mas, também, a credibilidade que atribuía às informaçóes veiculadas nesses papéis. Nesse sentido, talvez valha a pena recordar as observaçóes que faz D. Francisco quando se refere, no mesmo diálogo, ao modo como devem ser narrados os episódios contemporâneos, que parecem pressupor a consciência da necessidade imperiosa de o historiador proceder à interpretação de fontes e de informaçóes, suprindo deste modo a falta de distanciamento crítico inerente ao relato de acontecimentos próximos no tempo. Diz:

\footnotetext{
${ }^{20}$ Jean Colomès, Le dialogue 'Hospital das Letras' de D. Francisco Manuel de Melo, p. 94.

${ }^{21}$ Ecco politico. Responde en Portugal a la voz de Castilla y satisface a un papel anonymo ofrecido al rey Felipe el $I V$. Sobre los intereses de la corona lusitana, y del occeanico, indico, brasilico, ethiopico, arábico, pérsico y africano império. Lisboa: Paulo Craesbeeck, impressor das Ordenes Militares, 1645.

${ }^{22}$ João Pinto Ribeiro, Desengano ao parecer enganoso que se deu a Felipe III contra Portugal. Lisboa: Paulo Craesbeeck, 1645.

${ }^{23}$ Manifiesto de Portugal escrito por D. Francisco Manuel. Lisboa: Paulo Craasbeeck, 1647.

${ }^{24}$ António Camões Gouveia, «D. Francisco Manuel de Melo, polígrafo. Escrever, descrever, contar, falar e pintar», Da Pré-História à História. Homenagem a Octávio da Veiga Ferreira. Editorial Delta, 1987, pp. 391-410.

${ }^{25}$ Epanáphoras de vária história portuguesa a el rey Nosso senhor D. Afonso VI. Em cinco relaçóes de sucessos pertencentes a este reyno, que contem os negócios públicos, políticos, trágicos, amorosos, bélicos, triunfantes. Lisboa: Henrique Valente de Oliveira, Impressor d'ElRey Nosso Senhor, 1660; Declaración que por el reyno de Portugal ofrece el doctor Geronimo de Santa Cruz a todos los reynos y provincias de Europa contra las calumnias opublicadas de sus émulos. Lisboa: António Craasbeeck y Melo, 1663 e Demonstración que por el reyno de Portugal agora ofrece el doctor Geronimo de Santa Cruz, a todos los reynos y provincias de Europa en prueva de la declaracion por el mesmo autor y por el mesmo reyno a todos los reinos y provincias de Europa ya ofrecida contra las calunias publicadas de sus émulos y en favor de las verdades por el tiempo manifestadas. Lisboa: António Craasbeeck de Melo, 1664. [Relação dos sucessos da armada que a Companhia Geral de Comércio expediu ao estado do Brasil, Lisboa, 1650].

${ }^{26}$ Jean Colomès, Le dialogue 'Hospital das Letras' de D. Francisco Manuel de Melo, p. 137.
} 
Mas aqueles historiadores que se empregam na escritura de uma só acção, como se disséssemos a vida de um príncipe, o sucesso de uma guerra, a relação dos movimentos e a transferência de uma república, a estes tais afirmo ser lícito e obrigatório salpicar de sentenças, observaçóes e juízos a sua história, [...].

E ainda:

aqueles que só pintam uma acção particular, como nela não possam concorrer as cópias da variedade e estranheza de eventos que as primeiras histórias compreendem, é necessário que o que faltou de riqueza à narração, supra a erudição em nosso proveito. ${ }^{27}$

Recorde-se que, apesar de se tratar em grande medida de impressos compostos sob patrocínio, a informação incluída nas relaçôes de acontecimentos políticos e militares e nos manifestos que circulavam então dentro e fora do espaço peninsular era apresentada como verdadeira, um aspecto patente no número considerável de títulos iniciados com expressóes do tipo: "Verdadeira relação...» ou «Relaciò molt verdadera...», etc. Por outro lado, o curto espaço de tempo decorrido entre os acontecimentos e o seu relato ou o seu comentário nestes papéis, conferiu a estes últimos uma função noticiosa próxima do jornalismo (não é por acaso que se considera que o jornalismo português nasceu nessa época com a Gazeta da Restauração). Nesta ordem de ideias, os papéis sobre a revolta da Catalunha acima referidos constituíam, do ponto de vista de D. Francisco Manuel de Melo, o repositório de notícias mais actualizado de que poderia dispor.

$\mathrm{O}$ estudo exaustivo da forma como D. Francisco trabalha esses materiais excede os limites deste breve apontamento. Diga-se, contudo, que, como foi já observado por Tobella, a partir do cotejo entre estes textos e a História de los movimientos y separación de Cataluña de D. Francisco de Melo, se observa que o mais utilizado foi o Epitome, do qual o autor incluirá por vezes longas citaçóes que vai adaptando ao seu estilo próprio, por meio do acrescentamento de reflexôes, de aforismos, de consideraçóes sobre os objectivos ou as consequências de determinadas decisóes políticas ou, ainda, da atribuição de motivaçóes ou de emoçóes às personagens envolvidas, o que se traduz não apenas numa forma subtil de tomar partido, mas, também, num modo de questionar e de se distanciar dos dados veiculados por essas fontes.

Acontece ainda que as informaçóes colhidas quer no mesmo Epitome, quer nos outros textos acima indicados surjam resumidas, ou truncadas pela eliminação de pormenores, e que D. Francisco combine e sintetize informaçóes retiradas de mais de uma fonte. Inevitavelmente, a dependência destas relaçôes é sobretudo visível quando o historiador conta acontecimentos que não presenciou, não sendo de estranhar que reproduza algumas das imprecisóes transmitidas por estas: os erros que comete ao indicar a duração do cerco de Salses, por exemplo, ou o número de soldados pagos pela Catalunha nessa campanha foram claramente bebidos em Apoyos de la verdad catalana.

\footnotetext{
${ }^{27}$ Jean Colomès, Le dialogue 'Hospital das Letras' de D. Francisco Manuel de Melo, p. 137. Sublinhados nossos.
} 
Mas as publicaçóes de que se serviu constituem casos muito especiais no universo dos papéis da Restauração: trata-se de traduçôes para castelhano de papéis redigidos originalmente na Catalunha, em cataláo, que foram trazidos para Lisboa em 1641 pelo embaixador do Principado, tendo sido impressos nesta cidade em castelhano por ordem de D. João IV. É o que se pode deduzir do privilégio estampado em todos, sem variantes, onde se lê:

Manda el Rey N. S. que pello Dezembargo do Paço se despache licença, \& Priuilegio a Lourenço de Queiros liureiro, para fazer imprimir quatro livros sobre as cousas de Catalunha, que o Embaxador daquelle Principado presentou a S. Magestade, que offerecerá com esta portaria. Em Lisboa a 6. de Mayo de 641, Francisco de Lucena.

Os papéis abarcados por este privilégio coincidem com fontes identificadas por Estruch y Tobella. Trata-se, afinal, de peças relevantes da política de aproximação entre Portugal e a Catalunha tentada entre 1640 e 1645 pelos partidários da Restauraçáo, que fora iniciada poucos dias depois da aclamação de D. João IV, com o envio de mensagens e de embaixadas aos responsáveis pelo levantamento da Catalunha. Uma prova do empenhamento régio nessa aproximaçáo foi a singular rapidez com que, em 1641, se publicou a Relaçam da viagem do Padre Mestre Ignacio de Mascarenhas à Catalunha. Este relato da primeira embaixada portuguesa a estabelecer relaçóes diplomáticas com as autoridades catalãs obteve, em apenas três dias, as licenças necessárias do Desembargo do Paço, do Ordinário e da Inquisiçãa ${ }^{28}$. Mas, no caso dos papéis que aqui nos ocupam, o privilégio concedido a Lourenço de Queirós ilustra bem a proveniência de muitas das informaçóes contidas nos papéis: os enviados, embaixadores, mensageiros, espióes, etc. que se movimentavam então no espaço ibérico ${ }^{29}$.

A publicação de escritos dando notícias das vitórias do exército catalão ou da aliança franco-catalã em Lisboa, e dos feitos militares das forças portuguesas e dos progressos da sua diplomacia na cena internacional, em Barcelona, ocupou intensamente os prelos dos impressores ao serviço de ambas as causas, nos dois extremos da Península, entre 1641 e 1645. Tanto quanto pudemos apurar, deu origem a pelo menos quarenta títulos, redigidos em castelhano, catalão e português, várias vezes traduzidos e reimpressos numa e noutra cidade. Se do lado português é possível detectar a interferência directa do Rei, do lado catalão, como demonstrou Nuria Florensa i Soler, foi o próprio Consell de Cent a financiar a impressáo de propaganda escrita. Foi este organismo, por exemplo, que encomendou ao Padre Gaspar Sala Berart a escrita de três dos quatro opúsculos mencionados acima, que acabaram por ser

\footnotetext{
${ }^{28}$ Relação do sucesso que o Padre Mestre Inácio Mascarenhas teve na jornada que fez á Catalunha por mandado de S.M. D. João IV aos 7 de Janeiro de 1641. Lisboa, na Off. de Lourenço de Anveres, 1641.

${ }^{29}$ Já Brito Aranha, no Supplemento ao Diccionario bibliographico portuguez vol. XVIII. Lisboa: Imprensa Nacional, 1906, p. 200, comentou, acerca deste acervo: «A série de opúsculos impressos em Barcelona, como se tem visto, não é pequena; além de notável por ser muito pouco vulgar, serve também de estudo relativo ao desenvolvimento que então já tinham, naquella parte da península hispânica, as artes graphicas. São bellíssimos alguns existentes na vasta collecção da biblioteca nacional de Lisboa». Sobre o emprego de tácticas de espionagem no espaço peninsular durante estes anos veja-se Fernando Cortés Cortés, Espionagem e Contra-espionagem numa Guerra Peninsular 1640-1668. Lisboa: Livros Horizonte, 1989.
} 
reimpressos em Lisboa ${ }^{30}$. Por outro lado, tal como acontece no caso português, é possível identificar, na Catalunha, no mesmo período, um pequeno grupo de impressores que se colocaram ao serviço da causa catalá: Jaume Romeu, Jaume Mathevat, Gabriel Noguès e Pere Lacavallería dedicaram-se à tradução para castelhano e para catalão das relaçóes e manifestos portugueses, e enviaram, para Portugal, notícias e relaçóes em cataláo e castelhano, não só de textos produzidos na Catalunha, mas também de panfletos franceses.

A leitura dos quatro papéis que iniciaram esta circulação de impressos entre as duas regióes peninsulares permite entender o modo como foi delineada inicialmente a estratégia editorial da facção catalá, apostada num ataque simultâneo em várias frentes e na justificação da revolta e das lutas separatistas através de argumentos do foro do Direito, da Teologia e de natureza Político-Militar. Assim, Apoyos de la verdad catalana estrutura-se como uma resposta, no plano jurídico, aos argumentos postos a circular pela facçáo castelhana quanto à legitimidade jurídica e moral da revolta, apresentando excertos da propaganda oficial da coroa seguidos dos argumentos que os invalidariam; já na Proclamação da Catalunha os motivos de descontentamento do povo catalão são justificados pela passagem em revista da História do Principado, dos pactos que realizara no passado com outros reinos peninsulares e além-Pirenéus - nomeadamente com a França -, bem como dos direitos adquiridos ao longo dos tempos e do seu atropelo pelo governo de Filipe IV. Observe-se que, apesar das acusações de tirania, não há ataques directos ao monarca. A nível manifesto, os visados são os seus conselheiros: o nome mais citado é o do Conde Duque de Olivares, mas há também outros ministros e chefes militares acusados de instigarem o rei ao exercício da tirania.

Já a Notícia Universal da Catalunha, apesar de também se debruçar sobre a história da Catalunha, propóe uma visão providencialista dos factos. Aí a Catalunha é pintada como uma naçâo extraordinariamente católica, protegida por Deus, pelos santos e pelos mártires que nela nasceram e cujos túmulos abriga, e descrita como uma comunidade predestinada para uma missão espiritual singular, apenas realizável em liberdade, fora do jugo castelhano. Apesar da sua longa extensão, o seu tom e a sua estrutura recordam as dos sermóes da época, apresentando como provas para os argumentos invocados, quer exemplos retirados da vida dos santos e mártires catalães, quer relatos de prodígios e de episódios maravilhosos atribuídos à interferência divina. Por fim, o Epitome relata o comportamento dos exércitos castelhanos em batalhas ocorridas na Catalunha e no Rossilhão, denuncia o comportamento despótico dos seus chefes militares, a crueldade e o comportamento sacrílego dos soldados, justificando deste modo a organização da oposição catalã ao governo central e terminando com a relação circunstanciada dos confrontos militares com Castela ocorridos até à batalha de Montjuique.

Todos estes textos se encontram semeados de comentários de carácter moralizante, muitas vezes feitos sob a forma de aforismos, de máximas, de paralelos com provérbios, através dos quais os seus autores vão dando sentido aos factos narrados, marcando-os como acontecimentos dos quais é possível extrair verdades de natureza moral ou teológica, num

\footnotetext{
${ }^{30}$ Nuria Florensa i Soler, «La republica catalana en la guerra contra Felipe IV: el Consell de Cent: más que un gobierno municipal», Espacio, tiempo y forma, Série IV, Historia Moderna, no 12, 1999, pp. 181-198 e ainda, Nuria Florensa i Soler, «La Republica catalana de 1641: un foc d'encendalls» in Butlleti de la Societat catalana d'Estudis Històrics, $\mathrm{n}^{\circ}$ 15, 2004, pp. 75-88.
} 
esforço interpretativo que muito se aproxima do tal modo de escrever «uma história particular» de que fala D. Francisco no Hospital das Letras.

Do ponto de vista do historiador que, ao tempo, desejasse ser isento e verdadeiro - e D. Francisco afirma, logo no início da sua História da guerra da Catalunha que «la verdade es la que dicta, yo quien escribe; suyas son las razones, mías las letras ${ }^{31}-$, parece-nos que os relatos dos acontecimentos certificados pelos representantes dos dois povos peninsulares que se opunham ao poder central seriam certamente preferíveis a qualquer versão posta a circular por este último. Mas nas alusóes que faz à informaçáo retirada de papéis, Melo revela-se prudente, apontando lacunas - como quando menciona, no livro V, parágrafo 135 «un ayudante catalán, cuyo nombre ignoramos y aun lo callan sus relaciones» (p. 191) -, precisando referências - com no livro II, paragrafo 39: «Mr de Serińan (a quien algunos papeles catalanes llaman Serniá)» - ou, mesmo, discutindo a verosimilhança dos dados referidos, como acontece no parágrafo 113 , do livro IV quando diz:

Algunos papeles que se han escrito en Cataluña y han llegado a mis manos, impresos y manuscritos, quieren que Espernan capitulase com el Velez sin dar noticia al magistrado de lo que pretendía hacer; pêro no parece creíble que un hombre cuerdo y extrangero concertas ela reducción de una ciudad sin consentimiento de sus ciudadanos. ${ }^{32}$

Em jeito de conclusão, podemos dizer que, se é verdade que D. Francisco Manuel de Melo recorreu, para a escrita da sua história, a fontes ideologicamente enfeudadas, que apresentavam os factos de modo favorável a quem as encomendava, não é menos verdade que escolheu entre as opçóes possíveis aquelas que apresentavam a versão dos factos que considerou menos tendenciosa, a mesma, afinal, que foi aceite pelos dirigentes do partido que defendia. Ainda assim, não nos parece que ao fazê-lo tenha fugido aos seus objectivos como historiador, pois, como ele próprio dirá:

Ofrezco a los venideros un ejemplo, a los presentes un desengaño, un consuelo a los pasados. Cuento los accidentes de un siglo que les puede servir a éstos, aquéllos y esotoros com lecciones tan diferentes. ${ }^{33}$

\footnotetext{
${ }^{31}$ Estruch y Tobella, La Guerra de Catalunha, I \$5, p. 35.

${ }^{32}$ Estruch y Tobella, La Guerra de Catalunha, p. 155.

${ }^{33}$ Estruch y Tobella, La Guerra de Catalunha, p. 15.
} 

Série

Documentos

Imprensa da Universidade de Coimbra

Coimbra University Press

2010

- U

C • 